Vol. 1 No. 2 Oktober 2021 e-ISSSN : 2797-0159 |p-ISSN : 2797-0574

\title{
PENGADAAN TEMPAT PENYIMPANAN SEMENTARA (TPS) LIMBAH PADAT BAHAN BERBAHAYA \& BERACUN (B3) LABORATORIUM LINGKUNGAN SEKOLAH TINGGI TEKNIK LINGKUNGAN (STTL) MATARAM
}

\author{
ENIDA FATMALIA ${ }^{1}$, DINI YULIANSARI ${ }^{2}$, TAUFIK ABDULLAH ${ }^{3}$, TINA \\ MELINDA ${ }^{4}$ \\ 1,2,3,4 Sekolah Tinggi Teknik Lingkungan Mataram \\ Email : enidafatmalia@gmail.com
}

\begin{abstract}
ABSTRAK
Permasalahan di Laboratorium Lingkungan STTL Mataram saat ini yakni belum memiliki Tempat Pembuangan Sementara Limbah Padat Bahan Berbahaya dan Beracun (TPS LP-B3), yang dihasilkan baik pada saat Praktikum berlangsung ataupun alat-alat yang sudah tidak bisa digunakan kembali dan telah terkontaminasi oleh Bahan Berbahaya dan Beracun. Berdasarkan permasalahan tersebut Laboratorium Lingkungan STTL Mataram sudah seharusnya memiliki Tempat Penyimpanan Sementara terkhusus untuk Limbah Padat Bahan Berbahaya dan Beracun agar Limbah Padat Bahan Berbahaya dan Beracun yang dihasilkan tidak akan memberikan dampak yang negatif ke lingkungan Kampus apabila tidak memiliki Tempat Penyimpanan Sementara yang memadai. Tujuan pengabdian untuk merancang dan mengadakan Tempat Pembuangan Sampah Sementara Limbah Padat B3 Laboratorium di lingkungan STTL Mataram. Adapun metode yang digunakan. Adapun kegiatan yang dilaksanakan pada pengabdian ini adalah 1) Rancangan Tempat Pembuangan Sementara Limbah Padat Bahan Berbahaya dan Beracun (TPS LP-B3), 2) Penentuan Lokasi Pembangunan, 3) Proses Pemasangan Bata, 4) Proses Plesteran, 5) Proses Acian, 6) Pemasangan Tutup Plat Bordes, 7) Pemasangan Label TPS Limbah Padat B3. Adapun kesimpulan dari kegiatan ini adalah Produksi limbah B3 laboratorium STTL Mataram setiap tahun sebesar 0,26 $\mathrm{m}^{3}$, sehingga bangunan TPS Limbah B3 yang direncanakan berkapasitas $0,5 \mathrm{~m}^{3}$ layak dilaksanakan, serta Kegiatan Pengabdian yang dilaksanakan sebagian besar dapat berjalan sebagaimana mestinya, walaupun ada penyesuaian waktu dengan kondisi dan situasi lingkungan Kampus.
\end{abstract}

Kata Kunci: Pengadaan; Tempat Pembuangan Sementara; Limbah Padat B3.

\begin{abstract}
The current problem in STTL Mataram Environmental Laboratory is that it does not yet have a Temporary Disposal Site for Hazardous and Toxic Solid Waste (TPS LP-B3), which is produced either during the practicum or equipment that cannot be reused and has been contaminated by Hazardous and Toxic Materials. Based on these problems STTL Mataram Environmental Laboratory should have a Temporary Storage Place specifically for Hazardous and Toxic Solid Waste so that the Hazardous and Toxic Solid Waste produced will not have a negative impact on the campus environment if it does not have an adequate Temporary Storage. The purpose of the service is to design and organize a Temporary Waste Disposal Site for Laboratory B3 Solid Waste in the STTL Mataram environment. The method used. The activities carried out in this service are 1) Design of Temporary Disposal Sites for Hazardous and Toxic Solid Waste (TPS LP-B3), 2) Determination of Development Locations, 3) Brick Laying Process, 4) Plastering Process, 5) Acian Process, 6 ) Installation of the Bordes Plate Cover, 7) Labeling of B3 Solid Waste TPS. The conclusion of this activity is that the production of B3 waste from the Mataram STTL laboratory every year is $0.26 \mathrm{~m} 3$, so that the planned B3 Waste TPS building with a capacity of $0.5 \mathrm{~m} 3$ is feasible, and most of the Service Activities carried out can run as they should, although there are adjustments time with the conditions and situations of the Campus environment.
\end{abstract}

Keywords:Procurement;Temporary Disposal Site;Hazardous \& Toxic Solid Waste 


\section{PENDAHULUAN}

Berdasarkan Peraturan Pemerintah Republik Indonesia Nomor 101 tahun 2014, Bahan Berbahaya dan Beracun yang selanjutnya disingkat (B3) adalah zat, energi dan/atau komponen lain yang karena sifat, konsentrasi dan/atau jumlahnya, baik secara langsung maupun tidak langsung dapat mencemarkan dan/atau merusak lingkungan hidup, dan/atau membahayakan lingkungan hidup, kesehatan serta kelangsungan hidup manusia dan makhluk hidup lain. Laboratorium Lingkungan STTL Mataram merupakan salah satu unit yang terdapat di Kampus STTL Mataram yang menghasilkan Limbah B3 paling besar di area Kampus tersebut, limbah yang pada umumnya terbagi menjadi limbah cair dan limbah padat.

Tempat Penyimpanan Sementara yang disingkat selanjutnya sebagai TPS adalah tempat yang dijadikan sebagai penyimpanan sisa buang sebelum diangkut atau dilanjutkan ke pihak selanjutnya yaitu pihak pemanfaat. Sedangkan untuk penyimpanan Limbah B3 berdasarkan PP No. 101 Tahun 2014 tentang Pengelolaan Limbah Bahan Berbahaya dan Beracun tertulis pada pasal 13 hurub (b) yaitu fasilitas penyimpanan Limbah B3 yang sesuai dengan jumlah Limbah B3, karakteristik Limbah B3, dan dilengkapi dengan upaya pengendalian pencemaran lingkungan hidup, yang dimaksud adalah tertulis pada Pasal 15 sebagaimana dimaksud dapat berupa: a) Bangunan, b) Tangki/container, c) Silo, d) Tempat tumpukan limbah, e) Waste impoundment, dan f) Bentuk lainnya sesuai perkembangan ilmu pengetahuan dan teknologi Permasalahan di Laboratorium Lingkungan saat ini yaitu belum memiliki Tempat Penyimpanan Sementara untuk Limbah Padat B3 yang dihasilkan baik pada saat Praktikum berlangsung ataupun alat-alat yang sudah tidak bisa digunakan kembali dan telah terkontaminasi oleh Bahan Berbahaya dan Beracun. Berdasarkan permasalahan tersebut Laboratorium Lingkungan STTL Mataram sudah seharusnya memiliki Tempat Penyimpanan Sementara terkhusus untuk Limbah Padat Bahan Berbahaya dan Beracun agar Limbah Padat B3 yang dihasilkan tidak akan memberikan dampak yang negatif ke lingkungan Kampus apabila tidak memiliki Tempat Penyimpanan Sementara yang memadai.

Luaran yang diharapkan dari kegiatan ini adalah hasil pemikiran pada pengabdian ini dapat dipublikasikan pada jurnal nasional terakreditasi.

\section{METODE PELAKSANAAN}

1. Pelaksanaan kegiatan

$>$ Lokasi

$>$ Waktu pelaksanaan

$>$ Latar belakang peserta

: Lingkungan STTL Mataram

: Maret- April 2021.

: Mahasiswa STTL Mataram

\section{Metode}

a) Bahan-bahan

Bahan yang di gunakan dalam Pengadaan TPS Limbah B3 ini adalah :

1) Bata Merah

2) Semen

3) Pasir

4) Plamur

5) Cat Dasar

6) Cat Penutup

7) Las Plat Bordes untuk Penutup

8) Engsel

b) Alat-alat

1) Mesin bor

2) Gergaji

3) Linggis

4) Saringan pasir

5) Skop 
6) Cetok semen

c) Prosedur Pembuatan

1) Penentuan Lokasi Pembangunan

2) Proses Pemasangan Bata

3) Proses Plesteran

4) Proses Acian

5) Pemasangan Tutup Plat Bordes

6) Pemberian Label TPS

\section{HASIL DAN PEMBAHASAN}

Kegiatan pengabdian ini difokuskan di lingkungan STTL Mataram yaitu Pengadaan TPS Limbah B3 di Laboratorium Lingkungan STTL Mataram.Berdasarkan observasi lapangan yang dilaksanakan di Laboratorium Kampus STTL Mataram sebelumnya, limbah B3 yang diproduksi laboratorium, Lampiran I Peraturan Pemerintah no. 101 Tahun 2014, volume produksi limbah B3 padat setiap semester adalah sebesar $0,0574 \mathrm{~m}^{3}$, maka volume per tahunnya adalah $0,115 \mathrm{~m} 3$.

Berdasarkan perhitungan tersebut desain Tempat Penyimpanan Sementara Limbah B3 Padat yaitu bangunan beton permanen dengan ukuran volume isi bersih $0,8 \times 0,8 \times 0,8 \mathrm{~m}^{3}$ atau kapasitas isi sebesar $0,5 \mathrm{~m}^{3}$ yaitu diperhitungkan lima kali lebih besar dari Volume hitung awal dikarenakan produksi Limbah Padat B3 yang tidak menentu seiring berjalannya Praktikum dan pengujian baik dari Mahasiswa STTL maupun dari Luar, namun masih jauh dan tidak melebihi dari $50 \mathrm{Kg}$ per harinya. Maka selanjutnya, mengacu pada ayat (1) huruf b. Pasal 28 pada Peraturan Pemerintah no. 101 Tahun 2014, disebabkan produksi limbah B3 laboratorium STTL Mataram tidak lebih dari $50 \mathrm{~kg}$ per hari, maka STTL Mataram dapat menyimpan limbah B3 paling lama 365 (tiga ratus enam puluh lima) hari sejak Limbah B3 dihasilkan.

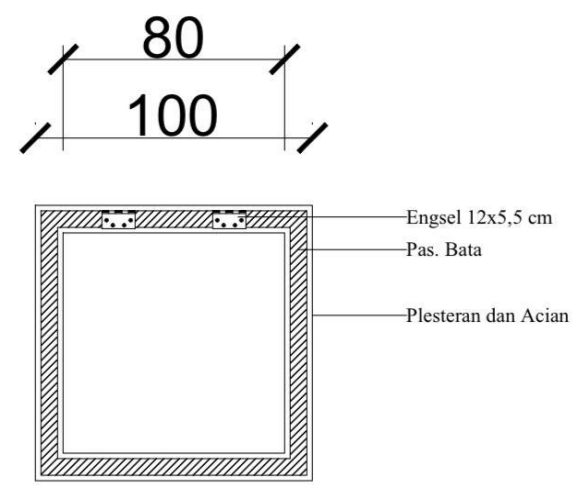

\section{Gambar Bak Sampah $1: 100$}

Gambar 1. Rencana Desain Bangunan TPS Limbah B3 


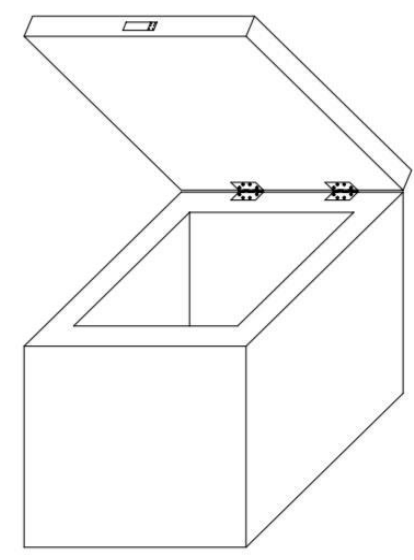

Gambar 3d

$1: 100$

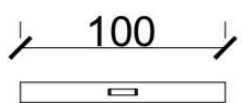

Tampak Depan Plat Bordes $1: 100$

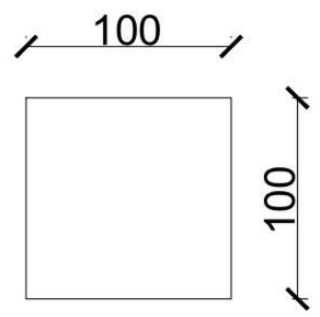

Tampak Samping $1: 100$

Gambar 2. Rencana Desain Bangunan TPS Limbah B3
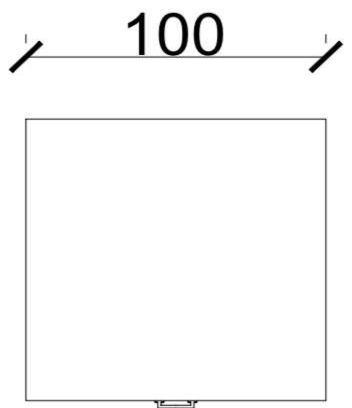

\section{Tampak Atas Plat Bordes \\ $1: 100$}

Gambar 3. Rencana Desain Tampak Atas Plat Bordes

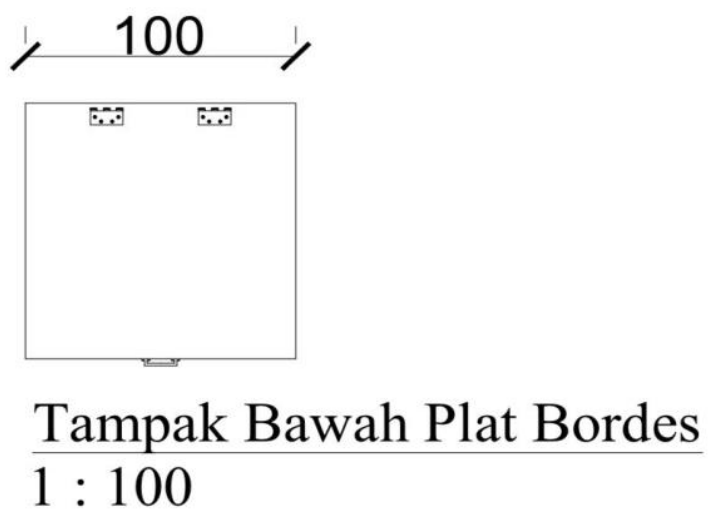

\section{Gambar 4. Rencana Desain Tampak Bawah Plat Bordes}

1) Penentuan Lokasi Pembangunan

Lokasi tempat pembangunan TPS-LB3 di kampus sekolah tinggi teknik lingkungan mataram dan dilkukan pembersihan dari rumput sampah dan berbagai macam bahan yang menghalangi dan dilanjutkan dengan perataan tanah dilokasi yang akan dibangun. 


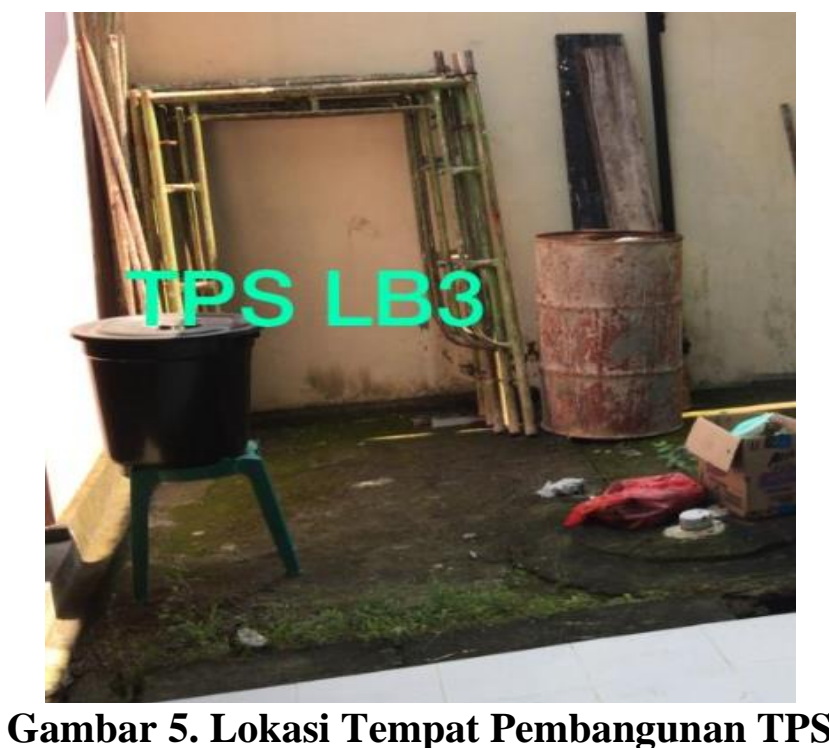

2) Proses Pemasangan Bata

Material untuk perkerjaan dinding relatif beragam diantaranya bata merah, batako, dan dinding partisi (gipsum dan multiplek). dalam pembangunan TPS-LB3 ini bata merah menjadi pilihan karna harganya terjangkau dan memiliki keunggulan, dan membuat dinding jauh lebih kuat dan berkualitas dibandingkan dengan material yang lain.

Pada pekerjaan dinding sebelum bata merah dipasang dilakukan dengan supaya pemasangan bata merah bisa rapi atau lurus dilanjutkan dengan pemasangan bata dengan tinggi $80 \mathrm{~cm}$ dan lebar $80 \mathrm{~cm}$ sesuai ukuran yang telah ditentukan.

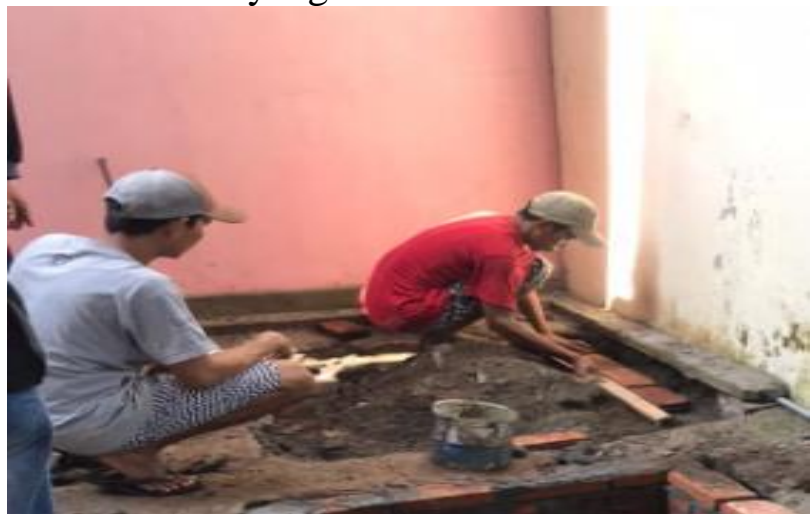

Gambar 6. Proses Pemasangan Bata

3) Proses Plesteran

Pekerjaan plesteran dilakukan setelah pekerjaan dinding yang terbuat dari pasangan bata merah atau batako atau dari bahan bata ringan selesai dilakukan selanjutnya barulah dilakukan pekerjaan acian sebagai lapisan akhir dari struktur dinding. Sebelum pelaksanaan pekerjaan plesteran dilakukan, bagian dinding yang akan dipasangi plesteran dibasahi atau disiram air terlebih dahulu kurang lebih dua jam sebelum pekerjaan plesteran dilakukan untuk memberikan kelembaban yang baik pada dinding. pekerjaan plesteran menggunakan bahan pasir yang dicampurkan dengan semen dengan komposisi 1: 5

Plesetran berfungsi:

a. Pekerjaan plesteran dinding dilakukan untuk mendapatkan kekuatan tambahan pada struktur dinding;

b. Plesteran dilakukan untuk memperlihatkan kerapihan dan keindahan pada suatu permukaan dinding

c. Plesteran secara konstruktif ditujukan untuk melindungi bidang dari cuaca seperti hujan, panas dan lainnya. 


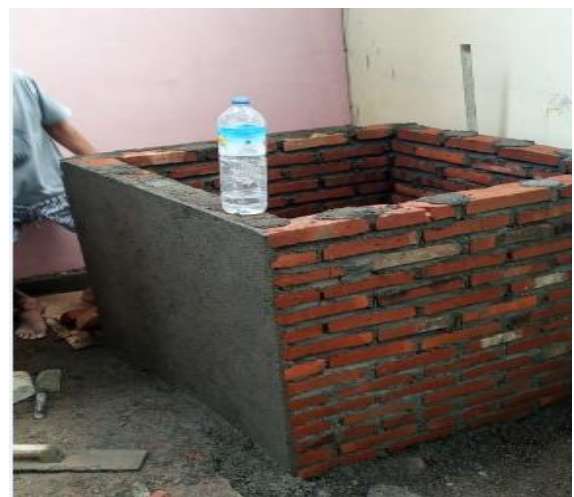

Gambar 7. Proses Plesteran

4) Proses Acian

Pekerjaan berikutnya adalah mengaci, bagian dalam proses pekerjaan dinding untuk menutup pori-pori atau memperhalus plesteran atau untuk menutupi adanya keretakan alami akibat penguapan. Sebelum pekerjaan acian dimulai, terlebih dahulu lakukan penyiraman agar acian mudah melekat pada plesteran. Bila pekerjaan acian telah selesai maka perlakuannya sama dengan pekerjaan plesteran. Material yang digunakan berbeda dengan plesteran karena tidak menggunakan pasir, yaitu hanya menggunakan campuran semen dan air saja. Untuk ketebalan acian adalah antara $1 \mathrm{~mm}$ hingga $3 \mathrm{~mm}$. Agar tidak terjadi retak pada acian, maka acian dapat dilakukan setelah plesteran kering dan tidak terjadi penyusutan lagi.

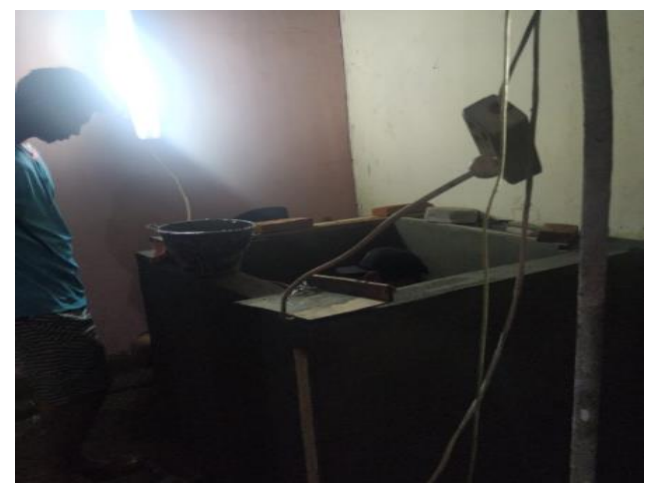

Gambar 8. Proses Acian

5) Proses Pemasangan Tutup

Berdasarkan PP No. 12 Tahun 2020 tentang Penyimpanan Limbah Bahan Berbahaya dan Beracun Pasal 11 ayat (2) poin d, dimaksud Atap dari bahan yang tidak mudah terbakar, maka digunakan Plat Besi Bordes. Agar pula terhindar dari Air Hujan dan Panas

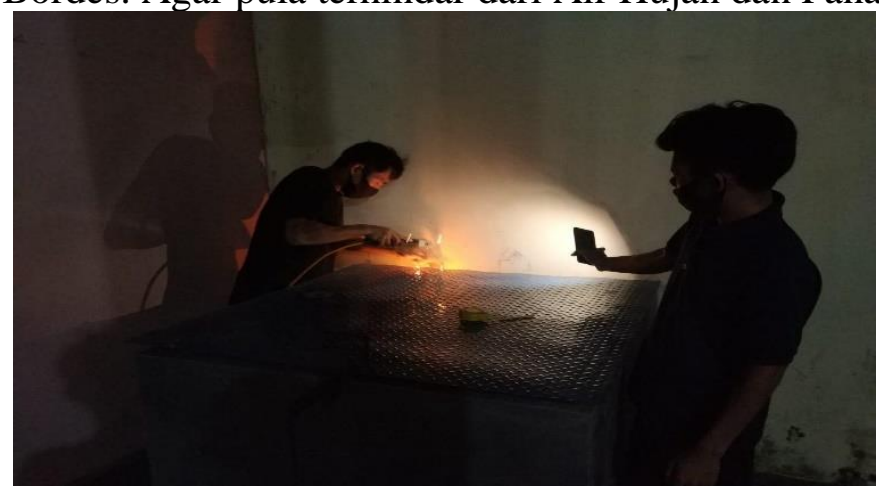

Gambar 9. Pemasangan Tutup 
6) Pemasangan Label dan Simbol

Berdasarkan Limbah B3 yang dihasilkan oleh Laboratorium Kimia dan Biologi dan Bahan Kimia yang mendominan dari data inventaris Bahan Kimia maka di pasang Papan Nama/Label yang berisikan titik Kordinat dan Simbol.

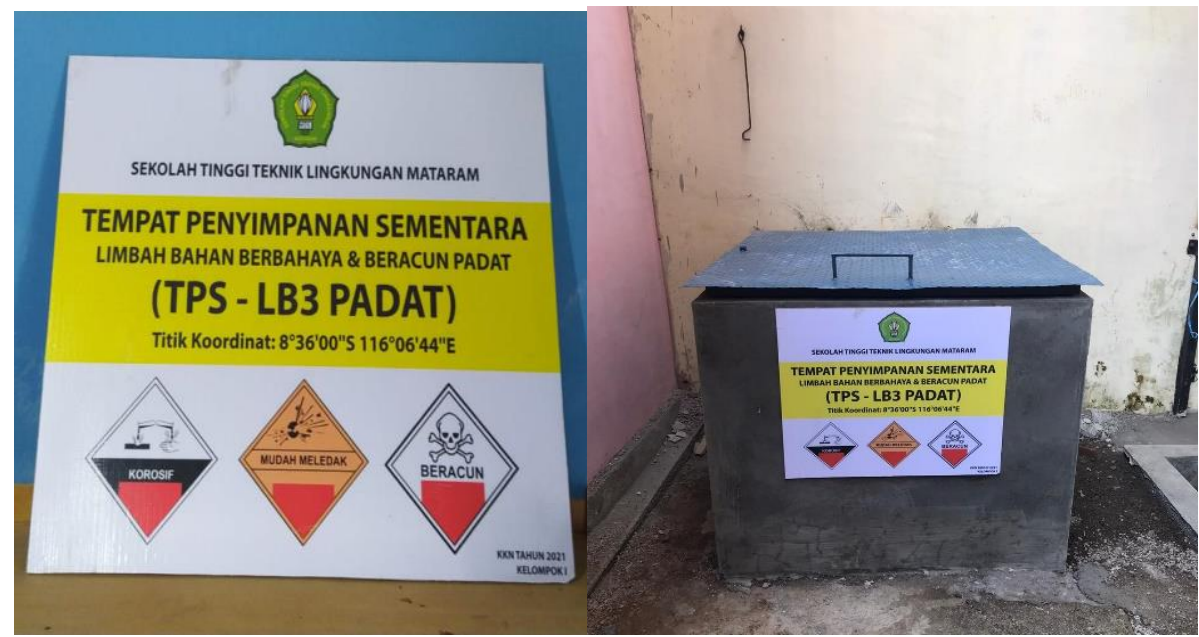

Gambar 10. Pemasangan Label dan Simbol

\section{KESIMPULAN}

1. Produksi limbah B3 laboratorium STTL Mataram setiap tahun sebesar $0,26 \mathrm{~m}^{3}$, sehingga bangunan TPS Limbah B3 yang direncanakan berkapasitas $0,5 \mathrm{~m}^{3}$ layak dilaksanakan.

2. Kegiatan Pengabdian yang dilaksanakan sebagian besar dapat berjalan sebagaimana mestinya, walaupun ada penyesuaian waktu dengan kondisi dan situasi lingkungan Kampus

\section{DAFTAR PUSTAKA}

Bilotta, G.S., R.E. Brazier. 2008. Understanding the influence of suspended solids on water quality and aquatic biota. Water Research. 42. 2849-2861.

Boyd, C.E. 1990. Water quality in ponds for aquaculture.Alabama Agricultural Experiment Station, Auburn University, Alabama. 482 p.

Effendi, H. 2003. Telaah Kualitas Air Bagi Pengelolaan Sumber Daya danLingkungan. Kanisius. Yogyakarta. 98 hal.

Hadyan Adi Purnomo, Evi Hendriarianti, Anis Artiyani, Pengelolaan Limbah Bahan Berbahaya dan Beracun (B3) di SMKN 4 Malang.

Mays, L.W.(Editor in Chief) 1996. Water resources handbook. McGraw-Hill.New York. p: 8.27-8.28.

Metcalf \& Eddy, Inc. 1991. Wastewater Engineering: treatment, disposal, reuse. $3^{\text {rd }}$ ed. (Revised by: G. Tchobanoglous and F.L. Burton). McGraw-Hill,Inc. New York

Niken Hayudanti Anggarini, Megi Stefanus, Prihatiningsih, Pengelolaan dan Karakterisasi Limbah B3 Di Pair Berdasarkan Potensi Bahaya, Majalah Ilmiah Aplikasi Isotop dan Radiasi, Vol. 5, No. 1 Februari 2014, ISSN 2087-5665.

Peraturan Menteri Pekerjaan Umum dan Perumahan Rakyat Republik Indonesia no. 28/PRT/M/2016 tentang Pedoman Analisis Harga Satuan Pekerjaan Bidang Pekerjaan Umum.

Peraturan Pemerintah Republik Indonesia No. 101 Tahun 2014 tentang Pengelolaan Limbah Bahan Berbahaya dan Beracun.

Umaly, R.C. dan Ma L.A. Cuvin. 1988. Limnology: Laboratory and field guide,Physicochemical factors, Biological factors. National Book Store,Inc. Publishers. Metro Manila. 322 p. 